\title{
A FILOSOFIA DA EXISTÊNCIA E A ENCARNAÇÃO COMO MISTÉRIO NOS PRIMEIROS TRABALHOS DE MAURICE MERLEAU-PONTY
}

\author{
THE EXISTENTIAL PHILOSOPHY AND INCARNATION AS MYSTERY IN THE FIRST WORKS BY \\ MAURICE MERLEAU-PONTY
}

\author{
Paulo Pimenta Marques*
}

\begin{abstract}
RESUMO
Este artigo mostra que a filosofia da existência do período inicial da obra de Merleau-Ponty revela uma problemática da encarnação e do mistério que visa a abertura da filosofia. Tal problemática assumirá transformações que resultarão, gradativamente, numa problemática da carne no debate ontológico do período final. Além das duas grandes obras do período inicial e algumas do período final, dar-se-á atenção especial a textos pouco conhecidos, tanto anteriores como imediatamente posteriores àquelas. Sempre em confronto com a Sexta Meditação metafísica, Merleau-Ponty elabora seu projeto intelectual através do exame do problema das relações entre a alma e o corpo, utilizando uma hermenêutica própria. $\mathrm{O}$ autor assume a "confusão" deixada de lado por Descartes, a qual foi revelada precisamente pela mistura da alma e do corpo. Tal perspectiva conduz à elaboração de uma nova questão que explicite a negligência da filosofia. Isto é, o idealismo cartesiano e kantiano destitui a realidade da verdade, a vida do pensamento e o existente do ser. Essa situação revela a necessidade de uma reforma da filosofia para instalá-la num território próprio, o terreno confuso da existência. E é assim que para explorar esse terreno indistinto ela deverá se fazer fenomenologia. Todavia, antes disso, através da perspectiva da filosofia da existência e da encarnação de Gabriel Marcel, Merleau-Ponty forja suas primeiras investidas contra a ontologia cartesiana do objeto. A problemática marceliana da encarnação - e sua afirmação central, "sou meu corpo" -, o orienta para uma reabilitação ontológica da experiência sensível. A variante epistemológica dessa mesma problemática, a noção de mistério, lança a encarnação contra a contemplação intelectualista, constitutiva do objetivismo. O autor radicaliza e aprofunda a originalidade de Marcel. A partir do corpo próprio, a existência como encarnação torna-se arquétipo de todo mistério enquanto sensível segundo a articulação passivo-ativo. O tema da encarnação passa a integrar toda obra do autor, alterando profundamente seu modo de filosofar.
\end{abstract}

PALAVRAS-CHAVE: Filosofia. Existência. Encarnação. Mistura. Mistério. Abertura.

\begin{abstract}
This article shows that the existential philosophy in Merleau-Ponty's works from the early period reveals incarnation and mystery issues which aim at the opening of philosophy. Such issues will bear some changes which will gradually result into the flesh issue in the ontological debate of the final period. Besides the two great works from the early period and some from the final one, special attention will be given to less known texts, both previous to and subsequent to those ones. Always confronting the Sixth Metaphysical Meditation, Merleau-Ponty develops his intellectual project through the exam of the problem of the relations between soul and body, using his own hermeneutics. The author assumes the "confusion" left aside by Descartes, which was precisely revealed by the mixture of the body and soul. Such perspective leads to a new question devised to explain the neglecting of philosophy. In other words, the Cartesian and Kantian idealism deprives reality of truth, life of thinking and the existent of being. This situation reveals the need of a reform of philosophy, so that it can be established in its own territory, the confusing one of existence. And that is why it to exploit this indistinct territory, it should turn itself into phenomenology. However, before that, through the perspective of Gabriel Marcel's philosophy of existence and incarnation, Merleau-Ponty tries his first approaches against the Cartesian ontology of the
\end{abstract}

\footnotetext{
* Mestre em filosofia pela UFMG-E-mail: marx.paulo@gmail.com
} 
object. The Marcelian issue of incarnation - and his final statement, "I am my body" -, guides him to an ontological recovery of the experience of the sensible. The epistemological variant of this same issue, the notion of mystery, drives incarnation against the intellectualist contemplation, which is constitutive of objectivism. The author goes more deeply and radically into Marcel's originality. With the notion of one's own body, existence as incarnation becomes the archetype of all mystery understood as sensible, and according to the active-passive connection. Thereafter the incarnation theme is present throughout the works of the author, deeply changing his way of philosophizing.

KEYWORDS: Philosophy. Existence. Incarnation. Mixture. Mystery. Opening.

\section{A leitura que Merleau-Ponty faz de Descartes}

Pouco tempo depois da publicação de A fenomenologia da percepção, em notas de cursos ministrados na École Normale Supérieure nos anos 1947-1948 (L'union de l'âme et du corps chez Malebranche, Biran et Bergson - que pontuaremos a seguir como UAC) sobre o problema da união da alma e do corpo em Descartes, Malebranche, Maine de Biran e Bergson, na primeira lição, Merleau-Ponty faz uma surpreendente afirmação a respeito da história da filosofia: "toda a história da filosofia é uma retomada pessoal pelo filósofo do problema que ele estuda; retomada subjetiva [...] mas não reflexão livre” (UAC, p. 11). Aqui evidentemente ele não quer dizer que não é possível haver qualquer objetividade em história da filosofia. Na realidade o que ele quer dizer é que não há um "método" puramente objetivo, e que se deve procurar uma "verdade que não se ofereça" a esse método. Em seguida, na mesma lição, o autor se refere à filosofia de Descartes. A recomendação é a mesma. Mas agora a ideia da presença da subjetividade na leitura de um filósofo toma mais forma. Diz ele que a verdade de Descartes

não é o que ele foi empiricamente; não é o resumo dos textos cartesianos; é, juntos, a totalidade do que ele escreveu e o modo como ele viveu, unidos pela intuição que podemos ter de uma verdade que ele procurou exprimir. Por exemplo, Descartes se colocou o problema da união da alma e do corpo; afirmou sua distinção, mas ele também pensou que essa distinção deveria ser esquecida na vida de todo dia. $A$ objetividade da história da filosofia não se encontra a não ser no exercício da subjetividade. $\mathrm{O}$ meio de se compreender um sistema é colocar-lhe as questões das quais nós mesmos nos ocupamos: é assim que os sistemas aparecem com suas diferenças, que eles atestam se nossas questões são idênticas àquelas que se colocavam seus autores. A história da filosofia é uma confrontação, uma comunicação com os sistemas, análoga àquela que podemos ter com os homens. Por mais que os filósofos escolham, sua escolha é sempre acompanhada, como na margem, de um vestígio daquilo que ele deixa de lado. Toda consciência de uma coisa é, ao mesmo tempo, consciência do que não é esta coisa. Cada escolha filosófica se destaca sobre o fundo do que não foi escolhido, e é através disso que os filósofos se comunicam; é este resíduo que mantém o diálogo entre os homens e, como consequência, a história da filosofia (UAC, p. 11-12, grifo nosso). 
Percebe-se assim que a aproximação entre a objetividade da história da filosofia e o exercício da subjetividade não significa buscar compreender Descartes tal como ele se compreendeu, ou como acreditamos que ele deveria tê-lo feito, recuperar o que ele disse, mas significa, ao contrário, expressar o que ele nos diz e mesmo imaginar o que ele poderia nos dizer ao ponto de nele encontrar certas intuições que nos proporcionem uma melhor compreensão de nós mesmos. Ou então devemos compreender que tais empreendimentos se dão sob a ótica daquilo que já aprendemos com a noção de impensado, de excesso, do resíduo resultante das diferenças que surgem quando rejeitamos a predominância da positividade da presença a si das ideias para que nelas vislumbremos o que as motivam e nos dão a pensar. E, mais ainda, se, como diz Merleau-Ponty acima, "toda consciência de uma coisa é, ao mesmo tempo, consciência do que não é esta coisa", devemos pensar outrem, ou repensá-lo, pensando a partir dele, levando em conta o que não é ele mesmo, as diferenças, as quais invariavelmente não se deixam apreender tão imediata e facilmente pois podem, por exemplo, aparecer como "unidade[s] discordante[s]" tal como nos dizem os exemplos abaixo.

Em três passagens bastante ilustrativas, de 1957, inéditas, e que integram o manuscrito La Nature et le monde du silence ${ }^{1}$, pertencentes ao último período do itinerário merleaupontyano, aprendemos um pouco mais sobre a perspectiva adotada por Merleau-Ponty, agora em contraste direto com a perspectiva adotada por Gueroult (1953). É assim que acerca de Descartes e o cartesianismo ele diz o seguinte:

\begin{abstract}
Há uma história do passado tal como ele se pensa e uma história do passado à luz do que sucedeu e de nossas questões. Querer suprimir essas e não colocar para Descartes a não ser questões cartesianas, é dizer que não acreditamos na filosofia. Há a história do passado tal como ele foi vivido ou expresso. E há uma história que dá a significação desse passado à luz do que sucedeu e em relação à nossas questões. Se não podemos colocar para Descartes a não ser questões cartesianas, é porque não há nada em comum entre ele e nós, é porque não há filosofia. (...) Ver-se-ia que há uma filosofia precisamente se não buscássemos tanto o sistema mas as intuições. (MERLEAU-PONTY apud SAINT AUBERT, 2005, p. 20-21).
\end{abstract}

'Cartesiano' não quer dizer que se vai fazer história da filosofia no sentido de Gueroult, i.e. exame interno do sistema e da integração das verdades. 1) Tomaria muito mais do que algumas horas por ano. 2) Isso seria referir-se ao que Descartes disse, renunciar a ver nele várias intuições, eventualmente discordantes, reduzi-lo sobre o plano único de uma ordem homogênea, talvez aumentar o que em Descartes

\footnotetext{
${ }^{1}$ Manuscrito, como sequência de trabalho, de 1957, reunido, com outros documentos, no volume Être et Monde, Bibliotéque Nationale, volume VI. Cf. Saint Aubert, 2008, p. 44 -53, para a publicação inédita das páginas de abertura do manuscrito, cuja importância está no fato de que ali, "pela primeira vez, Merleau-Ponty tem por objetivo propor uma ontologia" $(2008$, p. 41).
} 
é o menos importante. Para ver o mais importante deve-se talvez fazer o que Delbos não quer fazer, meditar sobre as passagens. 3) Isso seria renunciar à colocação em perspectiva, i.e. a ver em Descartes o exemplo de uma dificuldade que está localizada no sistema que é talvez a espinha do pensamento ocidental. Deixar-se-ia escapar ao mesmo tempo o mais próprio e o mais universal de Descartes ... (...). Portanto, reflexão livre sobre certos temas incontestavelmente cartesianos não para reconstituir sua organização na ordem, mas para valorizar sua unidade discordante e talvez propor novo começo ontológico (MERLEAU-PONTY apud SAINT AUBERT, 2005, p. 20).

Vê-se aqui uma tomada de posição pelo menos análoga às reflexões de 1947-48. É possível até que a referência de Merleau-Ponty a uma "reflexão livre" signifique aqui uma maior certeza quanto ao que significa "reflexão em outrem" ou "pensar segundo outrem", reflexão livre essa que, aparentemente, ele interditava anteriormente (UAC, p. 11), mostrando assim uma pequena hesitação em assumi-la. Mas o que importa destacar é a perspectiva de reflexão proposta, ou seja, a reflexão em outrem que busca o impensado de um autor, mais suas intuições e menos as ideias aparentemente presentes a si mesmas de forma transparente, permitindo uma maior convivência com as contradições que as operações constitutivas do Cogito e da imanência intelectual interditam sem mais considerações. É dessa forma que no texto inacabado, $O$ visível e o invisível, em uma nota de trabalho de 1959, Merleau-Ponty diz:

Há a verdade de Descartes, mas sob a condição de ser lida nas entrelinhas; a atmosfera do pensamento de Descartes, o funcionamento cartesiano; e isso não é imposição a Descartes de um ponto de vista exterior, à sua filosofia, de uma questão que não é a sua. Mostrar que há um absoluto, uma filosofia imanente à história da $\varphi$ e que, entretanto, não é reabsorção de todas as filosofias numa só, nem, de outra parte, ecletismo e ceticismo. Vê-se isso quando se consegue fazer da filosofia uma percepção, e da história da $\varphi$ uma percepção da história - Tudo se resume nisto: fazer uma teoria da percepção e da compreensão que mostre que compreender não é situar na imanência intelectual, que compreender é apreender pela coexistência, lateralmente, em estilo, e assim atingir de um golpe os pontos longínquos desse estilo e desse aparelho cultural. O que aí [nesse capítulo] vou dizer sobre a história da $\varphi$ antecipa o que direi sobre o Cogito e sobre o logos [...]. Não há senão antecipações, [...]. A filosofia como problemas concêntricos (MERLEAU-PONTY, 1964 , p. 242 ; p. $180^{2}$. Tradução modificada).

Portanto, destaca-se a ideia de que compreender para Merleau-Ponty não significa somente "situar na imanência intelectual", mas "apreender pela coexistência, lateralmente", mostrando, assim, que "a hermenêutica merleau-pontyana não é aquela de uma restituição científica dos autores que ela convoca" (SAINT AUBERT, 2005, p. 20), tal como se dá no

\footnotetext{
${ }^{2}$ As numerações separadas por vírgula que seguem as abreviaturas correspondem sequencialmente ao original e à tradução brasileira. O ponto e vírgula corresponde à separação entre partes citadas. Todas as traduções não indicadas nas referências, ou modificadas, são de nossa autoria.
} 
estilo de Gueroult. Ao contrário, Merleau-Ponty, pouco a pouco, constrói uma problemática pessoal, experimenta e progride, marca seu próprio caminho. Em outras palavras, ao ler um outro filósofo ele o faz menos como comentador, historiador ou professor de filosofia, e mais como o que é para ele ser um filósofo. Não se prendendo a um espírito escolar ele era um homem que levava a marca dos debates de seu tempo sempre atento a todas as áreas de pensamento. Ao examiná-las buscava constantemente vê-las sob uma nova ótica ontológica sempre em construção, a sua própria. Nesse sentido Descartes lhe forneceu o texto fundamental que iria permiti-lo trabalhar do começo ao fim de toda sua obra o problema que é, provavelmente, o mais importante da herança cartesiana: o problema das relações da alma e do corpo.

\section{O problema das relações da alma e do corpo}

Ao fazer uma revisão do sentido de suas pesquisas em filosofia, em entrevista dada a Georges Charbonier em 1959, Merleau-Ponty declara que "o ponto de partida de suas pesquisas foi no fundo bastante tradicional”, e que após seus estudos, concluídos em 1929, ele "se liga" ao problema das relações da alma e o corpo como a um problema que lhe interessava em especial, e que continuou nesse "sentido" durante quinze anos, "e é o resultado desse esforço que apareceu sob a forma de dois livros [...] que são todos os dois consagrados mais ou menos ao problema das relações da alma e do corpo" (MERLEAU-PONTY apud SAINT AUBERT, 2005, p. 18). Naquela época, impressionou-lhe o cartesianismo de seu "mestre" Léon Brunschivicg, o qual aceitava entre o espírito e o corpo, uma distinção categórica do que é consciência e do que é coisa, "a existência como coisa e a existência como consciência sendo opostas uma à outra”. Tal interesse de Merleau-Ponty é comentado por Gerard Lébrun em uma de suas notas para a tradução de J. Guinsburg e Bento Prado Júnior das Meditações de Descartes, publicada em 1973 (DESCARTES, 1973, p. 81-150). Lébrun destaca a importância dessa obra para a compreensão da filosofia de Merleau-Ponty. Mais exatamente ele comenta a primeira frase do famoso parágrafo da Sexta Meditação onde Descartes afirma "que não somente estou alojado em meu corpo, como um piloto em seu navio, mas que, além disso, lhe estou conjugado muito estreitamente e de tal modo confundido e misturado, que componho com ele um único todo" (DESCARTES, 1973, p. 144). Para Lebrun, "pode-se dizer, por exemplo, que a Phénoménologie de la Perception de Merleau-Ponty constitui, em 
certo sentido, um comentário dessas linhas"3.

Quase quarenta anos após esse comentário de Gerard Lebrun, também aprendemos com Emmanuel de Saint Aubert, em seu trabalho atual e bastante abrangente acerca de toda a obra de Merleau-Ponty ${ }^{4}$, que a problemática das relações da alma e do corpo constituiria uma motivação fundamental a partir da qual Merleau-Ponty teria não apenas arquitetado sua obra de 1945 mas alicerçado sua "intenção filosófica” e construído todo o seu "projeto intelectual”; sua origem estaria presente precisamente na passagem da Sexta Meditação, a qual MerleauPonty retoma criticamente ao longo de toda sua obra. A seguir apresentamos o texto preciso que Merleau-Ponty teria "sempre guardado no espírito". Trata-se da "versão francesa à qual ele sempre se refere, com tradução de duc de Luynes revista e aprovada por Descartes" (SAINT AUBERT, 2005, p. 24), de 1647:

\begin{abstract}
La nature m'enseigne aussi par ces sentiments de douleur, de faim, de soif, etc., que je ne suis pas seulement logé dans mon corps, ainsi qu'un pilote en son navire, mais, outre cela, que je lui suis conjoint très étroitement et tellement confondu et mêlé, que je compose comme un seul tout avec lui. Car, si cela n'était, lorsque mon corps est blessé, je ne sentirais pas pour cela de la douleur, moi qui ne suis qu'une chose qui pense, mais j'apercevrais cette blessure par le seul entendement, comme un pilote aperçoit par la vue si quelque chose se rompt dans son vaisseau; et lorsque mon corps a besoin de boire ou de manger, je connaîtrais simplement cela même, sans en être averti par des sentiments confus de faim et de soif. Car en effet tous ces sentiments de faim, de soif, de douleur, etc., ne sont autre chose que de certaines façons confuses de penser, qui proviennent et dépendent de l'union et comme du mélange de l'esprit avec le corps (DESCARTES, 1897-1909).
\end{abstract}

O texto em português que consultamos é a tradução de J. Guinsburg e Bento Prado Júnior, a partir do original da $1^{\text {a }}$ edição de $1641^{5}$, que apresentamos a seguir:

\footnotetext{
${ }^{3}$ Nota 175 , que é aqui reproduzida: "Frase capital. Descartes não estabeleceu que eu sou um entendimento + um corpo, porém que em mim há, além do mais, uma 'mistura' dessas duas substâncias. E esta mistura de fato corrige o dualismo de direito. A ideia de que sou totalmente corpo e totalmente espírito anuncia um tema fundamental da Antropologia moderna. Pode-se dizer, por exemplo, que a Phénoménologie de la Perception de Merleau-Ponty constitui, em certo sentido, um comentário dessas linhas" (DESCARTES, 1973, p. 144).

${ }^{4}$ Cf. Saint Aubert, 2004, 2005, 2006.

5 DESCARTES, 1973. Chamamos a atenção para a seguinte observação: essa tradução foi feita a partir do original da $1^{a}$ edição, Paris, 1641, conforme indicado no próprio volume da Editora Abril, cuja referência está incompleta. Essa edição não foi corrigida por Descartes. Porém, o que cabe aqui destacar é que, se comparadas, as duas versões, de 1641 e a de 1647 , não apresentam nenhuma diferença relativa à passagem em questão. Cf. Meditações sobre Filosofia Primeira / René Descartes; tradução: Fausto Castilho. - Ed. Bilíngue em latim e português - Campinas, SP: Editora da Unicamp, 2004. (Coleção Multilíngues de Filosofia UNICAMP - Série A - Cartesiana I). $1^{\mathrm{a}}$ reimpressão, 2008. Traduzido de: Oeuvres de Descartes, publiées par Charles Adam et Paul Tannery. Paris: Vrin, 1964-1974, vol. VII.
} 


\begin{abstract}
A natureza me ensina, também, por esses sentimentos de dor, fome, sede, etc., que não somente estou alojado em meu corpo, como um piloto em seu navio, mas que, além disso, lhe estou conjugado muito estreitamente e de tal modo confundido e misturado, que componho com ele um único todo. Pois, se assim não fosse, quando meu corpo é ferido não sentiria por isso dor alguma, eu que não sou senão uma coisa pensante, e apenas perceberia esse ferimento pelo entendimento, como o piloto percebe pela vista se algo se rompe em seu navio; e quando meu corpo tem necessidade de beber ou de comer, simplesmente perceberia isto mesmo, sem disso ser advertido por sentimentos confusos de fome e de sede. Pois, com efeito, todos esses sentimentos de fome, de sede, de dor, etc., nada são exceto maneiras confusas de pensar que provêm e dependem da união e como que da mistura entre o espírito e o corpo (DESCARTES, 1973, p. 144).
\end{abstract}

\title{
Comentando essa famosa passagem da Sexta Meditação em notas de cursos
} ministrados na École Normale Supérieure, aos quais já nos referimos acima, Merleau-Ponty afirma, na segunda lição, que "a questão da união da alma e do corpo não é em Descartes uma simples dificuldade especulativa como com frequência se supõe" (UAC, p. 13). Mais exatamente ao final de sua obra Descartes descobre o que deveria ter sido o seu ponto de partida, o que vem ameaçar e destruir não apenas suas primeiras meditações, mas todo o seu pensamento ${ }^{6}$. Contudo, ao invés de retroceder, Descartes reforça ainda mais sua ontologia para não vê-la arruinada. Dessa forma Merleau-Ponty vê toda a dificuldade aparecer na Sexta Meditação. Nela "a união nos é 'ensinada' pelos sentimentos de fome, de sede, etc... que se originam 'da mistura do espírito com o corpo'; ora, 'todos esses sentimentos [...] não são outra coisa senão certas maneiras confusas de pensar"' (UAC, p. 13). Isso significa que o problema para Descartes é "dar conta de um fato paradoxal: a existência do corpo humano" (UAC, p. 13), corpo que eu sou. Isso implica no fato de que "Descartes deveria se colocar o problema do corpo vivo, 'confundido e misturado' com a alma" (UAC, p. 13-14). Se o problema é esse, Descartes não o resolve, e sua opção é esquivar-se. O que é distinto na ordem da pureza só responde ao que é distinto e à pureza. A confusão permanece inacessível ao pensamento. Para Merleau-Ponty Descartes

não sustenta em nenhum lugar que se possa pensar a união. Não há nada a dizer. As noções que ele introduz a esse respeito são míticas no sentido platônico da palavra: destinadas a lembrar ao ouvinte que a análise filosófica não esgota a experiência ${ }^{7}$. A

\footnotetext{
${ }^{6}$ Cf. UAC, p. 13 - 16, para os comentários de Merleau-Ponty a respeito da contradição no interior das Meditações, mais exatamente entre a Primeira e a Sexta Meditações, além de várias referências a outras passagens fundamentais de Descartes a respeito do problema da união da alma e do corpo.

${ }^{7}$ Evidentemente deve-se compreender a noção de "experiência" no sentido buscado por Merleau-Ponty através de sua fenomenologia, a qual revelará um plano situado aquém das construções e das idealizações da ciência, ou do pensamento objetivo.
} 
união não pode ser conhecida a não ser pela união (UAC, p. 15) ${ }^{8}$.

Traça-se assim o destino dos dualismos antropológicos que Merleau-Ponty vai constantemente contestar. Esses dualismos, na perspectiva do pensamento puro, desemaranham com suas obras de clarificação a complexidade da "mistura" presente em "nossas instituições" e em "nossa vida expressiva". Ao fazerem isso,

\begin{abstract}
[eles] tornam incompreensíveis a unidade do ser humano, e não chegam a pensar seus laços com o mundo e com outrem. A partir do conceito de carne ${ }^{9}$, MerleauPonty tenta justamente elaborar uma filosofia do laço, compreendida como unidade antropológica, relação ética e ontológica (laços do homem consigo mesmo, com outrem e com o mundo, que engaja até o laço do ser e do nada). Se Sartre atinge um ponto culminante entre os pensamentos que Merleau-Ponty quer, assim, combater, Descartes será o seu principal fundador, numa ontologia secretada na medida de seu abandono de nosso forro passivo-ativo no regime da confusão que não estamos encarregados de pensar (SAINT AUBERT, 2005, p. 18).
\end{abstract}

Dessa forma, Merleu-Ponty conduz seu pensamento primeiro para uma problemática da encarnação através de uma filosofia da existência e do corpo para depois passar à problemática da carne, ou da união e do laço perdidos, em sua última fase.

Se é assim, Merleau-Ponty vê na Sexta Meditação uma boa e uma má perspectiva do cartesianismo. Boa porque essa passagem representaria o lugar onde Descartes estabelecera o espaço para a meditação sobre a encarnação, má porque tendo encontrado "o mais precioso dos tesouros" - a constatação da mistura, da confusão, ou da união, e a possibilidade de pensála - ele não o explora "e o enterra para sempre” (SAINT AUBERT, 2005, p. 25). É esse texto fundamental que vai permitir Merleau-Ponty trabalhar do começo ao fim de toda sua obra as questões relativas à possibilidade de pensar a união, ou de pensar a possibilidade de abertura da dimensão da filosofia. O conflito cartesiano se desenha para Merleau-Ponty desde o "pensamento confuso" mencionado n' A estrutura do comportamento em 1942, até atingir a rica expressão dos "emblemas" e de um "tremor prontamente superado" em $O$ olho $e$ o espírito (MERLEAU-PONTY, 1964b, p. 56; 2004, p. 32), assim como o "subentendido" da linguagem como "véu esticado" de O visível e o invisível, em 1960 (MERLEAU-PONTY, 1964a, p. 252, 1984, p. 188).

O pensamento confuso dessa mistura aparece n' A estrutura do comportamento com a

\footnotetext{
${ }^{8}$ Cf. Carta a Elizabeth de 28 de junho, 1643, A.T. III, p. 693. Cf. Também Respostas às IV objeções, A.T. VII, p. 228-229.

$9 \quad$ Cf. Saint Aubert, 2005, 2008.
} 
crítica à ideia segundo a qual à filosofia não cabe tratar do "problema das relações da alma e do corpo", pois este, diz Merleau-Ponty, "se colocaria apenas no nível de um pensamento confuso" (MERLEAU-PONTY, 1967, p. 217; 2006, p. 311); como diz Descartes, a percepção, por exemplo, deve ser remetida "à ordem da vida, ou do pensamento confuso" (MERLEAUPONTY, 1967, p. 233; 2006, p. 334). Ou ainda,

já que o mundo físico e o organismo podem ser pensados apenas como objetos de consciência ou significados, o problema das relações da consciência com suas 'condições' físicas ou orgânicas só existiria no nível de um pensamento confuso que se atém a abstrações; ele desaparece no domínio da verdade, onde subsiste originalmente apenas a relação do sujeito epistemológico com seu objeto. Nisso consistiria o único tema legítimo da reflexão filosófica (MERLEAU-PONTY, 1967, p. $220 ; 2006$, p. 316).

$\mathrm{Na}$ obra mais conhecida dos primeiros trabalhos, a Fenomenologia da percepção, de 1945, Merleau-Ponty remete para a psicologia do século XIX os elementos principais do conflito cartesiano ao tratar do corpo: "apreendo meu corpo" dessa forma, diz ele, como um "objeto-sujeito", com a capacidade de "ver" e de "sofrer", mas essas "representações confusas" eram vistas como "curiosidades psicológicas", ou exemplos de um "pensamento mágico", cujas leis a psicologia e a sociologia estudam para ligá-las como objeto de ciência ao "sistema do mundo verdadeiro". As ambiguidades do corpo,

\begin{abstract}
enquanto corpo tocante e corpo tocado não podiam [...] ser traços de estrutura do próprio corpo; não afetavam sua ideia, tornavam-se os 'caracteres distintivos' dos conteúdos da consciência que compõem nossa representação do corpo: esses conteúdos são constantes, afetivos e bizarramente emparelhados em 'sensações duplas', mas, com exceção disso, a representação do corpo é uma representação como as outras e, correlativamente, o corpo é um objeto como os outros. Os psicólogos não percebiam que, ao tratar assim a experiência do corpo, eles apenas adiavam, em consonância com a ciência, um problema inevitável (MERLEAUPONTY, 1945, p. 111; 1999, p. 140).
\end{abstract}

Em suas reflexões posteriores às duas obras, de outubro a novembro de 1948 MerleauPonty participa de sete conferências, ou "conversas" radiofônicas, encomendadas pela Rádio Nacional Francesa com o objetivo de divulgar seu pensamento. Nestas, ele apresenta várias críticas a Descartes, uma das quais - retirada de uma passagem dos textos redigidos pelo próprio autor e que eram lidos durante as transmissões - nos mostra claramente o conflito da "mistura" ou da "confusão" da alma e do corpo. Eis a passagem retirada da "V Conversa", denominada "O homem visto de fora": 
Encontramos tudo em Descartes, como em todos os grandes filósofos, e é assim que ele, que havia distinguido rigorosamente o espírito do corpo, chegou a afirmar que a alma era não apenas o chefe e o comandante do corpo, como o piloto em seu navio, e sim tão estreitamente unida a ele que ele sofre, como observamos quando dizemos que temos dor de dente. Só que, segundo Descartes, quase não podemos falar dessa união da alma e do corpo, podemos apenas experimentá-la pela prática da vida; para ele, qualquer que seja nossa condição de fato e mesmo se de fato vivemos, segundo seus próprios termos, uma verdadeira "mistura" do espirito com o corpo, isso não nos tira o direito de distinguir absolutamente o que está unido em nossa experiência, de manter em direito a separação radical do espirito e do corpo, que é negada pelo fato de sua união e, finalmente, de definir o homem sem se preocupar com sua estrutura imediata e tal como ele aparece a si mesmo na reflexão: como um pensamento esquisitamente vinculado a um aparelho corporal, sem que a mecânica do corpo ou a transparência do pensamento sejam comprometidas pela sua mistura. Pode-se dizer que, a partir de Descartes, exatamente aqueles que seguiram com mais fidelidade seu ensinamento nunca deixaram de perguntar-se, precisamente, como pode nossa reflexão, que é reflexão sobre um determinado homem, livrar-se das condições as quais este parece sujeito em sua situação inicial (MERLEAU-PONTY, Conversas - 1948: Con, p. 46 - 47, tradução corrigida).

Essa elaboração do conflito revela o que nos parece a determinação de Merleau-Ponty de levar a cabo seu projeto. E essa determinação é confirmada pois ela também aparece no último texto do autor publicado em vida: numa bela elaboração do conflito cartesiano em $O$ olho e o espírito ${ }^{10}$, numa passagem do terceiro capítulo, o autor comenta as relações entre o pensamento e a visão em profundidade. Merleau-Ponty tem seu pensamento já estabelecido no interior do terreno ontológico, e não trata ali exatamente da Sexta Meditação, mas de uma outra obra, a Dióptrica. Ao final o autor ironiza a posição tomada por Descartes em relação ao problema da união entre a alma e o corpo. Acompanhemos a passagem de $O$ olho e o espírito:

Essa visão de fato e o 'há' que ela contém não perturbam no entanto a filosofia de Descartes. Sendo pensamento unido a um corpo, ela não pode por definição, ser verdadeiramente pensamento. Podemos praticá-la, exercê-la e, por assim dizer, existi-la, mas dela nada podemos tirar que mereça ser dito verdadeiro. Se, como a rainha Elizabeth, quisermos à força pensar algo a esse respeito, não há senão que retomar Aristóteles e a Escolástica, conceber o pensamento como corporal, o que não se concebe, mas é a única maneira de formular diante do entendimento a união da alma e do corpo. Em verdade, é absurdo submeter ao entendimento puro a mistura do entendimento e do corpo. Esses pretensos pensamentos são os emblemas do "uso da vida", as armas eloquentes da união, legítimas com a condição de não serem tomadas por pensamento. São os indícios de uma ordem da existência - do homem existente, do mundo existente - que não nos compete pensar. Essa ordem não marca em nosso mapa do Ser nenhuma terra incógnita, não restringe o alcance de nossos pensamentos, porque está sustentada, como este, por uma Verdade que funda tanto sua obscuridade quanto nossas luzes. É até aqui que devemos prosseguir

10 Cf. Sartre, 1961, em "Merleau-Ponty vivant": "há $O$ olho e o espírito que diz tudo contanto que saibamos decifrá-lo" (p. 372). 
para encontrar em Descartes algo como uma metafísica da profundidade: pois essa verdade, não assistimos a seu nascimento, o ser de Deus é, para nós, abismo ... Tremor prontamente superado: para Descartes é tão inútil sondar esse abismo quanto pensar o espaço da alma e a profundidade do visível. Sobre todos esses assuntos, estamos desqualificados por posição. Tal é o segredo de equilíbrio cartesiano: uma metafísica que nos dá razões decisivas para não mais fazermos metafísica, que valida nossas evidências limitando-as, que abre nosso pensamento sem dilacerá-lo (MERLEAU-PONTY, 1964b, p. 54-56; 2004, p. 31-32; grifo nosso).

Nota-se a referência ao "tremor prontamente superado" onde se compreende que na Sexta Meditação são abertas, para em seguida se fecharem definitivamente, todas as questões trabalhadas ao longa da obra merleau-pontyana e que a última filosofia, a "filosofia da carne", assumiria, plenamente, de forma definitiva. Acreditamos que seja assim. E da mesma maneira que em vários outros textos também em sua obra inacabada, $O$ visível e o invisível, MerleauPonty descreve a ameaça da confusão, ou da mistura ao pensamento filosófico:

O espírito é o que pensa, o mundo é o que é pensado, não se poderia conceber nem a imbricação de um no outro, nem a confusão de um com o outro, nem a passagem de um para o outro, nem mesmo o contato entre eles (...). A filosofia recusa, pois, como desprovido de sentido, todo entrelaçamento do mundo com o espírito e do espírito com o mundo. (...). Desse modo, com a correlação de princípio entre o pensamento e o objeto de pensamento, estabelece-se uma filosofia que não conhece nem dificuldades, nem problemas, nem paradoxos, nem reviravoltas: uma vez por todas, apreendi em mim, com a pura correlação daquele que pensa com aquilo que ele pensa, a verdade de minha vida, que também é a verdade do mundo e a das outras vidas. De uma vez por todas, o ser-objeto se coloca diante de mim como o único dotado de sentido para mim, e toda inerência dos outros a seus corpos e a de mim mesmo ao meu é recusada como confusão - de uma vez por todas, o ser-si me é dado na adequação de meu pensamento a ele mesmo, de sorte que também desse lado não se cogita de levar a sério a mistura do espírito com o corpo (MERLEAUPONTY, 1964a, p. 71-73; 1984, p. 54-55).

Noutro exemplo retirado de uma passagem também de $O$ visível e o invisível, quase ao final do primeiro capítulo intitulado "Reflexão e interrogação", encontramos Merleau-Ponty não apenas às voltas com o problema da filosofia reflexiva ${ }^{11}$, mas, mais do que isso, com o problema de ver a filosofia apartada do campo da experiência e a necessidade dela se "misturar":

Se finjo pela reflexão encontrar no espírito universal a premissa que desde sempre sustentava minha experiência, isto somente é possível esquecendo o não-saber do início, que não é nada, que não é tampouco verdade reflexiva, e que também é preciso explicar. Só me foi dado chamar o mundo e os outros a mim e tomar o caminho da reflexão, porque desde o início estava fora de mim, no mundo, junto aos outros, sendo que a todo momento essa experiência vem alimentar minha reflexão.

\footnotetext{
${ }^{11}$ No sentido das filosofias idealistas.
} 
Esta é a situação total que uma filosofia deve explicar. Ela só o fará admitindo a dupla polaridade da reflexão, e que, como dizia Hegel, entrar em si também é sair de si (MERLEAU-PONTY, 1964a, p. 74; 1984, p. 56).

Dessa forma, essas passagens de $O$ visível e o invisível nos mostram que o problema do interdito à filosofia originado pelo conflito cartesiano e o desafio de enfrentá-lo faz um claro apelo à filosofia para a recuperação da fenomenalidade do mundo, a necessidade de incluir a experiência na reflexão. Também, nos comentários do autor na entrevista de 1959, citada acima, a respeito de seus interesses iniciais em filosofia, ele se refere à distinção categórica entre a alma e o corpo, ou entre o corpo e o espírito, na relação do pensamento com ele mesmo e com outrem, e isso já no momento de sua filosofia nascente, muito antes dos textos de $O$ visível e o invisível. Ele diz:

quando o espírito reflete sobre sua verdadeira natureza, ele se percebe somente como
pura consciência, pensada no sentido cartesiano, e é ele mesmo que é ainda o
espectador da relação do espírito e do corpo. Ele a vê, pensa, constitui, isso faz parte
do universo do pensamento, mas não é uma ligação do pensamento com outra coisa
que ele mesmo. E é essa imanência filosófica do pensamento com ele mesmo que
sempre chocou-me, que sempre pareceu-me insuficiente, de modo que desde a época
de meus estudos propus-me trabalhar sobre esse problema, das relações do espírito
com o que não é ele: como torná-las compreensíveis, como torná-las pensáveis
(MERLEAU-PONTY apud SAINT AUBERT, 2005, p. 18).

Há, por conseguinte, um problema comum entre as duas fases do pensamento do autor, a inicial e a final, e esse problema é o problema da necessidade da filosofia se modificar. Além disso, se levarmos em conta a definição da intencionalidade husserliana como a elaborada por Levinas, de que a intencionalidade designa a "maneira para a consciência de conter idealmente outra coisa que ela" (LÉVINAS, 1974, p. 22), Merleau-Ponty, ao falar de seu interesse inicial acerca do problema das relações do espírito com o que não é ele, nos leva a crer que ele também já se refere à noção de intencionalidade, ou de fenomenologia, a qual ele começou a buscar ao final de seus estudos universitários em 1929.

Portanto, é no contexto do problema das relações entre a alma e o corpo, na perspectiva do conflito cartesiano interior à Sexta Meditação, que compreendemos que a leitura que Merleau-Ponty faz de Descartes traduz "uma nova questão": como é possível "que haja um setor que não se possa pensar?” (UAC, p. 15). Este é o escândalo que despertou a intenção filosófica de Merleau-Ponty.

Ao examinarmos as primeiras obras, vemos que essa nova questão é claramente 
abordada. N' A estrutura do comportamento (1942): "Descartes não procurou integrar o conhecimento da verdade e a prova da realidade, a intelecção e a sensação" (SC, p. 212, $305)^{12}$; e na obra de 1945, a Fenomenologia da percepção: "a questão é sempre a de saber como posso ser aberto a fenômenos que me ultrapassam e que, todavia, só existem na medida em que os retomo e os vivo" (PhP, p. 417, 487). Portanto, Merleau-Ponty elabora - e aqui pode-se dizer do começo ao fim de sua obra -, o problema que talvez resuma a "negligência essencial da filosofia, seja na abordagem do ser, da verdade ou dela mesma" (SAINT AUBERT, 2005, p. 48). A tradição cartesiana, e, com ela, a tradição idealista, destituem a realidade da verdade, a vida do pensamento, o existente do ser.

Essa interpretação tem sua origem no período de formação do autor, quando ele descobre e se aproxima da "filosofia da existência" da época, assim como da fenomenologia husserliana. Merleau-Ponty busca desde os primeiros trabalhos reabrir para a filosofia todos os setores da vida, contra Léon Brunschvicg, e sob a influência de Gabriel Marcel e Max Scheler. Em outras palavras, "como permitir ao entendimento puro a definição do ser e do verdadeiro se ele não é fundamentado para conhecer o mundo existente", como se pode ler em Resumés de cours (MERLEAU-PONTY, 1968, p. 100), visto que "a união não pode ser conhecida senão pela união" (UAC, p. 15), ou, ainda, que "é a vida que compreende validamente a vida" (MERLEAU-PONTY, 1968, p. 100)?

Tal situação quer dizer que a filosofia deve ser reformada e tomar como território próprio, de acordo com Sens et non-sens, "o terreno confuso da existência" (MERLEAUPONTY, 1966, p. 313). É assim que para explorar esse terreno indistinto ela deverá se fazer fenomenologia. "Nós aprendemos a reconhecer a ordem dos fenômenos. Estamos misturados ao mundo e aos outros em uma confusão inextricável” (MERLEAU-PONTY, 1945, p. 518; 1999, p. 610). E inextricável significa aqui que tal implicação não pode ser explicada, pois corre o risco de desaparecer. Isso porque o estilo da fenomenologia de Merleau-Ponty diminui a tarefa da analítica intencional de desimplicar o implicado, para destacar "a arte do começo

\footnotetext{
${ }^{12}$ Merleau-Ponty comenta o problema da "mistura": "A experiência de meu corpo como 'meu, que põe em descrédito a metáfora aristotélica da alma como um piloto em seu navio, é explicada por sua vez através de uma 'mistura' real do 'espírito com o corpo'. Assim, o universo da consciência revelado pelo Cogito e que parecia dever encerrar em sua unidade até a percepção era apenas, no sentido restrito, um universo de pensamento: ele dá conta do pensamento de ver, mas o fato da visão e o conjunto dos conhecimentos existenciais permanecem fora dele. A intelecção que o Cogito havia encontrado no coração da percepção não esgota seu conteúdo; na medida em que a percepção se abre para um 'outro', na medida em que é a experiência de uma existência, ela provém de uma noção primitiva que 'só pode ser entendida por ela mesma' de uma ordem da 'vida' na qual as distinções do entendimento são pura e simplesmente anuladas" (SC, p. 212, 304-305).
} 
filosófico: reconhecer a ligação e admirar-se com ela, descrevê-la e interrogá-la, experimentála e colocá-la a prova, o que supõe ao mesmo tempo uma participação e uma distância, o complexo de uma 'fé interrogativa"' (SAINT AUBERT, 2005, p. 50), cuja formulação será tentada nos últimos textos. Porém, já nos primeiros textos tal tentativa se dará sob a forma de uma "fé originária da percepção" (MERLEAU-PONTY, 1945, p. 66; 1999, p. 85), ou "fé primordial” (MERLEAU-PONTY, 1945, p. 468; 1999, p. 548). É assim que no mesmo ano de publicação da Fenomenologia da percepção, em 1945, em uma conferência dada no Institut des hautes études cinématographiques, publicada em Sens et non-sens, Merleau-Ponty já expressa essa necessidade de uma reforma da filosofia:

\footnotetext{
Uma boa parte da filosofia fenomenológica ou existencial consiste em se admirar com essa inerência do eu no mundo e do eu no outro, em nos descrever esse paradoxo e esta confusão, em fazer ver a ligação do sujeito e do mundo, do sujeito e dos outros, ao invés de explicá-la, como faziam os clássicos (MERLEAU-PONTY, 1966, p. 104-105; grifo nosso).
}

Portanto, para que a "filosofia contemporânea" faça "aparecer a união do espírito e do corpo, do espírito e do mundo e a expressão de um no outro", ela não pode se constituir em "encadear conceitos, mas em descrever a mistura da consciência com o mundo, seu engajamento em um corpo, sua coexistência com os outros" (MERLEAU-PONTY, 1966, p. 104-105), nesse terreno confuso que é a existência.

\section{A filosofia da existência e o mistério da encarnação}

\subsection{A existência como encarnação}

Como já mencionamos, o projeto intelectual de Merleau-Ponty inicia-se após seus estudos, por volta do final dos anos 1920 e início dos anos 1930. Essa é uma época de grande depressão econômica mundial, da ascensão do fascismo, época que põe em cheque a civilização capitalista e burguesa. Tal situação desperta a necessidade de renovação do pensamento moral e político de intelectuais franceses de inspiração cristã, para então atingir o círculo intelectual de Merleau-Ponty. Politicamente de esquerda na época de estudante e por algum tempo depois um católico praticante, ele se insurge contra o idealismo moralizante presente no pensamento liberal dominante na universidade francesa, o qual não era capaz de 
fazer frente às adversidades do momento, era preciso buscar alternativas. Em meio a tal situação o jovem Merleau-Ponty frequenta os pensamentos, por exemplo, de Emmanuel Mounier, Jacques Maritain, Paul Claudel, e de outros intelectuais ligados às correntes neotomistas e neo-escolásticas da época, os quais contestam a burguesia e o pensamento idealista de inspiração cartesiana e kantiana. A contestação merleau-pontyana de inspiração marxista viria mais tarde sob a influência de Georges Lukács e "Alexandre Kojève, cujas palestras sobre Hegel ele [Merleau-Ponty] assistiu no final dos anos 30" (MATTHEWS, 2010, p. 162) ${ }^{13}$. Portanto, desde o início de seu projeto intelectual as questões filosóficas de MerleauPonty andam juntas com suas preocupações pessoais e os debates políticos de sua época.

O interesse de Merleau-Ponty pela aproximação entre filosofia e experiência vivida pode ser traduzido pelo pensamento sobre a existência concreta que resultou na filosofia existencial ou da existência ${ }^{14}$. Em uma conferência de $1959^{15}$ - no qual ele faz uma revisão de seu itinerário intelectual e em particular de sua filosofia da existência -, Merleau-Ponty diz que a entrada da filosofia da existência na frança deu-se por meio de Gabriel Marcel (18891973), através das influências que chegavam através de Husserl, Heidegger e Jaspers. É no período posterior a seus estudos, de 1930 a 1939, quando ele já leciona filosofia nas províncias e prepara sua tese de doutorado que se deu a "entrada na filosofia da existência tal como ela nos vinha [...], [diz ele], em particular, através da revista Esprit", a qual, sob "o incentivo de Mounier", com frequência tratava de "temas da filosofia da existência", como relata Philosophie et existence. (MERLEAU-PONTY, 2000, p. 253). E continua: "em reação contra uma filosofia de tipo idealista, kantiana ou cartesiana, a filosofia da existência se traduziu primeiro para nós através da predominância de um outro tema, o tema da encarnação" (MERLEAU-PONTY, 2000, p. 254) ${ }^{16}$.

Tal tema aparece principalmente sob a influência da leitura que Merleau-Ponty faz do pensamento da encarnação de Gabriel Marcel, o qual tem um papel fundamental nas primeiras

13 Sobre o Marxismo de Merleau-Ponty, em geral, cf. p. 161-171; cf. também DOSSE, 2008, para a formação geral de Merleau-Ponty na perspectiva das ciências humanas.

14 Merleau-Ponty faz uma distinção entre filosofia da existência ou pensamento existencial, que é o seu, e o existencialismo, que ele rejeita, tal como principalmente Sartre o desenvolveu a partir de 1945. Cf. PhEx, 247 248.

15 "La philosophie de l'existence": trascrição de uma conferência de Merleau-Ponty na Maison canadienne da cidade universitária de Paris, em 14 abril de 1959, com emissão radiofônica em 17 novembro de 1959, em Conférence de Radio-Canada. Cf. Parcours deux 1951 - 1961: P2, p. 247-266.

${ }^{16}$ Cf. Moutinho, 2004, p. 264-293, para uma visão detalhada a respeito da questão da encarnação do ponto de vista dos conceitos de "reflexão" e "constituição". 
oposições merleau-pontyanas ao idealismo francês representado por Léon Brunschvicg. Além disso Merleau-Ponty descobre a obra do pensador francês antes de conhecer a obra de Husserl e de Heidegger, e será marcado constantemente pelas leituras de "Existence et objectivité" (MARCEL, 1927a) e do Journal métaphysique (MARCEL, 1927b) iniciando sua empreitada contra o objetivismo ${ }^{17}$. Nesse sentido, sua filosofia se volta contra o modo de conhecer que outorga como "essencial à filosofia [ater-se a] uma definição da inteligência que a fecha sobre si, [o que é] talvez garantir-lhe uma espécie de transparência e como uma atmosfera protegida, mas isso é, talvez, também, renunciar a conhecer o que é”, como se lê em Christianisme et ressentiment. (MERLEAU-PONTY, 1997, p. 33). Ou seja, para MerleauPonty, a filosofia deve engajar-se a favor do pensamento da existência. Tratava-se, diz ele em sua resenha de 1936 sobre o livro de Gabriel Marcel Être et avoir ${ }^{18}$, "de pensar o que a maioria dos filósofos tomaram como resíduo. Pois, não estamos 'equipados' para pensar a existência, e todo o trabalho resta a fazer" (MERLEAU-PONTY, 1997, p. 39). É preciso criticar o "universo da ciência" representado pelo "criticismo de M. Brunschvicg", para o qual, sobre aquilo "que não foi reduzido em objeto de ciência, não podemos nada dizer, nada pensar, nem mesmo que ele existe". Contra isso, opõe-se a ideia de que "a objetividade não pode esgotar a existência" (MERLEAU-PONTY, 1997, p. 32).

Portanto, a influência de Gabriel Marcel sobre Merleau-Ponty orienta sua concepção de ser em direção à existência sensível. Nesse sentido, uma passagem encontrada no primeiro fascículo do Journal de la métaphysique o marcará profundamente. Para Gabriel Marcel,

quando se observa a evolução das doutrinas metafísicas desde por volta de um
século, impressiona-nos constatar quanto os filósofos idealistas concordam, em
geral, em reduzir ao mínimo o papel da existência, do índice existencial na economia
geral do conhecimento [...]. Esta presença sensível da coisa que, se ela não se
confunde com sua existência, aparece pelo menos para uma reflexão não prevenida

\footnotetext{
${ }^{17} \mathrm{Na}$ perspectiva do "objetivismo", tal como compreendido por Merleau-Ponty em seus primeiros trabalhos, a natureza encontre-se completamente submetida ao sujeito transcendental. O mundo é visto como "o conjunto de relações objetivas [trazidas] pela consciência", não há nada "no mundo que seja estranho ao espírito" (SC, 1, 1). Estabelece-se, assim, a distinção clara e distinta entre o objetivo e o subjetivo. É a crítica a esse objetivismo, ou pensamento objetivo, que está em jogo em A estrutura do comportamento (1942). Nessa obra, através da noção de estrutura, ou de forma, Merleau-Ponty prefigura uma "nova maneira de ver o ser". É através da análise da "objetividade científica" que o autor indica um "fundo não relacional” (Signes: S, p. 190, 166) de que essa objetividade depende, o qual é da ordem perceptiva, sem contudo elaborar uma fenomenologia da percepção. É a obra de 1945, Fenomenologia da percepção, que revelará esse fundo.

18 Resenha da obra de Gabriel Marcel, Être et avoir, Paris, Montaigne, 1935, [Éditions Universitaires, 1991], apresentada sob o mesmo título, Être et avoir, em 1936, primeiramente publicada em La vie intellectuelle, $8^{\mathrm{e}}$ année, nouvelle série, t. XLV, octobre 1936, p. 98-109, e retomada em Parcours 1935 - 1951: P1, p. 35-44.
} 
como sua manifestação, sua revelação a mais imediata: eis o que uma filosofia voltada ao mesmo tempo para as ideias e para os objetos tenderá necessariamente a escamotear. [...] A existência aparece doravante como superada - ou reduzida - ou talvez simplesmente escamoteada (MARCEL, 1927, p. 309-311).

É esse interesse pela presença sensível da coisa, pela existência enquanto existência sensível que, além de marcar tão profundamente os primeiros trabalhos de Merleau-Ponty, vai ser por ele trabalhado ao longo de toda sua obra, revelando, já no início de sua aparição, algo como o estilo da ontologia dos textos da última fase, da famosa "reabilitação ontológica do sensível" (MERLEAU-PONTY, 1960, p. 210). Quanto à presença da existência em toda obra do autor é o corpo que se apresenta agora como elemento mais importante dos primeiros trabalhos.

É assim que se a existência encontra seu arquétipo na existência sensível, essa última encontra o seu arquétipo no corpo vivido, "meu corpo", ser sensível por excelência ao qual Gabriel Marcel consagra as últimas páginas de seu artigo - "sou meu corpo" (MARCEL, 1927b, p. 323). A filosofia que minimiza o papel da existência na sua teoria do conhecimento obedeceria a uma rendição da inteligência diante da existência. Como diz Saint Aubert,

ocorre um recalque da existência, sobretudo do ser sensível, e no mais alto ponto do ser carnal: Merleau-Ponty retoma essa sucessão ordenada ao longo de uma obra que faz justamente se transformar uma na outra - e se completar - uma filosofia da existência, uma fenomenologia da percepção, e uma 'psicanálise ontológica' (SAINT AUBERT, 2005, p. 80).

Portanto, a aproximação entre filosofia e existência ganha mais contorno. MerleauPonty comenta, retrospectivamente, essa introdução do corpo como "arquétipo da existência sensível”. Diz ele em 1959:

\footnotetext{
Nos primeiros escritos de Gabriel Marcel, no seu Journal métaphysique por exemplo, ou mesmo nos seus artigos que ele publicou ainda anteriormente, esse tema era colocado em relevo de um modo que nos impressionou a todos. $\mathrm{Na}$ filosofia, habitualmente, o corpo, meu corpo, é considerado como um objeto do mesmo modo que o corpo dos outros, do mesmo modo afinal que o corpo de um animal, do mesmo modo que afinal uma mesa, um objeto exterior. Eu, eu sou espírito, e em face de mim há portanto esse corpo que é um objeto. O que Gabriel Marcel sustentava era precisamente que não é nada disso e que se considero atentamente meu corpo não posso fingir que ele seja apenas um objeto. Em certos aspectos ele é eu, 'sou meu corpo', dizia ele. E não é apenas o corpo que interferia pois com ele o que era colocado sob o olhar de nosso espírito era de um modo geral o mundo sensível (MERLEAU-PONTY, 2000, p. 254).
} 
É evidente nessa passagem a visão alargada do corpo como "emblema" do "mundo sensível", corpo este que não se refere ao corpo objetivo da fisiologia ou da ciência, mas ao "corpo próprio", sobre o qual Merleau-Ponty demonstrava seu interesse nos primeiros projetos de tese. Com isso, a título de ilustração, tomemos um exemplo da concepção de “corpo próprio" retirado da Fenomenologia da percepção e que começa a ser desenvolvida na obra anterior, A estrutura do comportamento, embora, em certa medida, tal concepção já esteja anunciada nas resenhas dos anos 1930.

Tratando da síntese do corpo próprio na obra de 1945 Merleau-Ponty compara o corpo “à obra de arte” (MERLEAU-PONTY, 1945, p. 176; 1999, p. 208). Ele não o compara a um "objeto físico", mas a "um romance, um poema, um quadro, uma peça musical" (MERLEAUPONTY, 1945, p. 177; 1999, p. 209). Para ele o corpo não é "a lei de um certo número de termos co-variantes" própria do "universo da ciência", mas "um nó de significações vivas" (MERLEAU-PONTY, 1945, p. 177; 1999, p. 210). O corpo, a obra de arte, são “indivíduos", isto é, "seres em que não se pode distinguir a expressão do expresso, cujo sentido só é acessível por um contato direto e que irradiam sua significação sem abandonar seu lugar temporal e espacial” (MERLEAU-PONTY, 1945, p. 177; 1999, p. 209-210). Há uma "configuração", uma "maneira de ser fundamental" própria destes seres. É o que compreendemos se nos voltarmos para a semelhança e convergência entre a busca de um filósofo e a busca do pintor. Se a ciência pode provar suas teses através do "cálculo" e “medidas" conhecidas de todos nós, diz Merleau-Ponty em A dúvida de Cézanne de 1945, “Cézanne, um artista, um filósofo devem não apenas criar e exprimir uma ideia, mas ainda despertar as experiências que a enraizarão nas outras consciências" (MERLEAU-PONTY, 2004, p. 33, 135).

Além disso Merleau-Ponty ainda nos mostra como o corpo, do ponto de vista do tema da existência e da encarnação, ainda apresenta desdobramentos que estão na base da evolução de seu pensamento. Tal é o caso da questão do "mistério" também tomada de Gabriel Marcel.

\subsection{As relações entre encarnação, problema e mistério}

Ainda na conferência de 1959 Merleau-Ponty traça um quadro da história pessoal de sua própria pesquisa e quanto ela é tributária do pensamento de Gabriel Marcel. Dando destaque em sua apresentação à própria filosofia da encarnação de Gabriel Marcel ele diz que 
ela implica em uma verdadeira refundação da filosofia e de seu método através da distinção entre problema e mistério, voltando-se dessa forma para a reelaboração da questão de outrem, da vida coletiva e da história.

Diz Merleau-Ponty que o tema da encarnação "não é apenas uma matéria ou um objeto de reflexão", mas "uma maneira de filosofar" (MERLEAU-PONTY, 2000, p. 255): rompe-se "o face a face cartesiano da existência como consciência e da existência como coisa"; a encarnação "abre o espaço do mistério que imbrica sobre seus próprios dados, e faz ruir o muro da objetividade que me desligava de outrem" (SAINT AUBERT, 2005, p. 83; destaque nosso). Pode-se dizer que as noções de encarnação e mistério passam a andar juntas.

Merleau-Ponty faz uma breve descrição da diferença entre problema e mistério tal como lhe parecia ser a posição de Gabriel Marcel e a qual era por ele assumida. Um problema, diz ele, "é uma questão que me coloco e essa questão eu a resolvo considerando diferentes dados que me são exteriores" tal como o faria para "saber como construir uma ponte", por exemplo. "Considero os dados do problema e tento encontrar o desconhecido". Já em filosofia o problema toma a forma de um "mistério" visto que "trata-se de uma outra coisa, porque em filosofia tratamos (...) de um espécie de problema muito singular". Aquele que o coloca "está ele mesmo engajado. Ele não é o espectador do problema, ele é tomado no empreendimento" (MERLEAU-PONTY, 2000, p. 255).

Portanto, se com isso esclarece-se apenas um pouco mais a relação entre encarnação e mistério, o que aprendemos com Saint Aubert, em referência a Jean Wahl, esclarece mais nitidamente a questão. Em seu comentário a respeito dessa ideia fundamental em Gabriel Marcel, diz Jean Wahl: “A encarnação como o Cogito, e mesmo com mais razão do que o Cogito, é um fato primitivo, mas um fato primitivo que não pode propriamente falando ser pensado" (1932, p. 237). Visto que essa afirmação foi feita antes da publicação de $\hat{E} t r e$ et avoir, ela não corresponde precisamente ao pensamento de Gabriel Marcel. Ao contrário de Jean Wahl, diz Saint Aubert, deve-se compreender que

\footnotetext{
o mistério não é a obscuridade daquilo que não se pode pensar, aquilo além do qual não há nada e que se deve abandonar para a vida não filosófica. Ele não é uma porta fechada marcada por proibido entrar, nem o segredo de um percurso iniciático, mas o inacabamento daquilo além do qual há sempre mais para pensar. $O$ mistério ontológico - e é isso que Merleau-Ponty vai cultivar até em seus últimos escritos -é a profundidade de um espaço de transição e de transgressão. Ele não assinala em direção a um ser do qual o homem estaria desligado, não evoca em primeiro lugar um abismo entre nós e o ser, mas antes esse excesso de proximidade que MerleauPonty chamará de "a promiscuidade do ser". No mistério o conhecimento abraça o
} 
que o envolve, penetra um ser que é envolvente em razão mesmo de nossa situação fundamental de seres encarnados (SAINT AUBERT, 2005, p. 91; grifo nosso).

Destacamos aqui essa ideia de "mistério ontológico" no sentido de "um espaço de transição e de transgressão", pois ela se constitui como uma característica que ajudará Merleau-Ponty a identificar o modo de abordar os paradoxos presentes nos seus primeiros trabalhos. Com isso avancemos um pouco mais nessa aproximação entre encarnação e mistério, tratando, brevemente, do problema da "contemplação intelectualista", a qual foi criticada por Merleau-Ponty por tentar manter o face a face cartesiano.

\subsection{A contemplação intelectualista}

O mistério descarta o conhecimento face a face de um objeto para um sujeito, rompe toda "bipartição dentro-fora" para dar-se numa ligação ao ser como "envolvente-envolvido", uma expressão que Merleau-Ponty usa na última fase de sua obra. Saint Aubert nos ensina que a crítica de Gabriel Marcel à "contemplação intelectualista” estende-se à distinção presente, por exemplo, em "Russel [ entre] knowledge about e knowledge by acquaintance" (2005, p. 93). Merleau-Ponty adota essa perspectiva desde a introdução do artigo de 1936 (MERLEAUPONTY, 1997, p. 35-36). Este tem o estilo não apenas de uma resenha, mas de uma contestação ao idealismo francês. Já na abertura do artigo o autor dispara sua crítica à Segunda Meditação de Descartes ao contestar a "contemplação intelectualista", inaugurando dessa forma a crítica do "espectador estrangeiro" 19 , a qual seria desenvolvida n' A estrutura do comportamento. Para Merleau-Ponty o senso comum e os filósofos tomaram "por tipo ideal do conhecimento humano nossa contemplação de objetos inanimados, coisas indiferentes, e que não nos tocam. Quando de minha janela, vejo os homens que caminham pela rua ..." (MERLEAU-PONTY, 1997, p. 35). Os filósofos, diz ele,

se estabeleceram numa 'atitude espetacular' (Marcel, 1935, p. 25) que despojava o objeto de seu aspecto humano, de suas investidas sobre nós, ao mesmo tempo que ela desprendia o sujeito de situações tais como a esperança, o desespero, a promessa, a invocação, onde ele está tão inclinado para o outro que dele torna-se inseparável (MERLEAU-PONTY, 1997, p. 37).

\footnotetext{
${ }^{19}$ Cf. Parcours deux, p. 12.
} 


\subsection{A existência como encarnação torna-se mistério ou enigma}

Contra essa ideia de contemplação, ou de uma "atitude espetacular", compreende-se que a perspectiva do pensamento da encarnação de Gabriel Marcel significa uma renovação da noção de mistério enquanto desvinculada de sua "significação religiosa" para dar-lhe uma "consistência filosófica", isto é, o inesgotável visto positivamente. Como diz Saint Aubert, aqui “os mistérios não são verdades que nos ultrapassam, mas verdades que nos compreendem" (2005, p. 94-95). A abordagem de Marcel, para Merleau-Ponty, é ainda original no sentido de "proceder a partir do corpo" e de fazer da encarnação o arquétipo de todo mistério. Isto é, o corpo é misterioso enquanto sensível segundo a articulação passivoativo do termo. Em outras palavras, ao assumir o ponto de vista de Gabriel Marcel no que diz respeito à problemática da encarnação, Merleau-Ponty radicaliza e aprofunda o pensamento deste, mas não sem críticas ${ }^{20}$. As repercussões se desenrolam desde a "figura da integração" em A estrutura do comportamento até às expressões como "a natureza enigmática do corpo próprio" na Fenomenologia da percepção (MERLEAU-PONTY, 1945, p. 230; 1999, p. $267)^{21}$; passa pelos textos intermediários ${ }^{22}$ e chega ao último texto publicado, $O$ olho $e o$ espírito $^{23}$. A existência como encarnação torna-se mistério ou enigma, transformando-se no foco central da fenomenalidade buscada pelo autor.

Portanto, o tema da encarnação passa a integrar a obra do autor alterando profundamente seu modo de filosofar na busca de uma reforma da filosofia. Nesse sentido, compreende-se tanto o surgimento desse novo tipo de conhecimento, já presente em Gabriel Marcel, o conhecimento fenomenológico e a perspectiva da intencionalidade, como a opção merleau-pontyana pelo estudo da percepção e, ainda timidamente, do desejo. Além da fenomenologia de Gabriel Marcel, a de Max Scheler e, especialmente, sua concepção de

\footnotetext{
${ }^{20}$ Cf. Saint Aubert, 2005, p 95-97, para uma crítica ao pensamento de Gabriel Marcel a partir de seus conceitos e que repercutirão no pensamento de Merleau-Ponty já no final dos anos quarenta.

${ }^{21}$ Note-se que a sinonímia entre as expressões "enigma" e "mistério" já aparecem na resenha de 1936; cf. EtAv, p. 40.

${ }^{22}$ Cf. S, p. 290, 259; A prosa do mundo: PM, p. 111, 106.

${ }^{23} \mathrm{OE}$, p. 18,$17 ; 21,18$. No período posterior à Fenomenologia da percepção, é a "figura nascente da 'imbricação"' que seguirá na mesma direção. Merleau-Ponty desenvolve e "aprofunda" o quadro formado pela "abordagem do mistério como imbricação generalizada", representada pelos três "domínios de manifestação" que são a encarnação - ou a união da alma e do corpo - o amor e o mal (Saint Aubert, 2005, p. 93). Nos anos 1957-1959, ele se serve de Gabriel Marcel ao desenvolver sua própria ontologia 'contra a 'ontologia cartesiana' e 'a analítica sartreana do Ser e do Nada"' (Cf. Saint Aubert, 2005, p. 94-99, para uma descrição das relações entre Merleau-Ponty e Gabriel Marcel no que diz respeito ao movimento que vai da encarnação à carne).
} 
"intencionalidade" 24 desempenharão um papel fundamental na construção do projeto merleaupontyano para uma filosofia da existência ou filosofia fenomenológica, na busca de uma maior abertura da filosofia, tarefa iniciada nos primórdios dos anos 1930.

\section{Referências}

DESCARTES, René. Oeuvres Philosophiques. Alquié, F. (org.). 3 vls. Paris: Garnier, 1963.

DESCARTES, René. Meditações. Int. de Gilles-Gaston Granger. Prefácio e notas de Gérard Lebrun. Tradução de J. Guinsburg e Bento Prado Júnior. São Paulo: Abril Cultural, 1973 (1 ${ }^{\text {a }}$ edição), p. 81-150. (Col. Os pensadores).

DESCARTES, René. Meditações sobre Filosofia Primeira / René Descartes; tradução: Fausto Castilho. - Ed. Bilíngue em latim e português - Campinas, SP: Editora da Unicamp, 2004. (Coleção Multilíngües de Filosofia UNICAMP - Série A - Cartesiana I). $1^{\text {a }}$ reimpressão, 2008. Traduzido de: Oeuvres de Descartes, publiées par Charles Adam et Paul Tannery. Paris: Vrin, 1964-1974, vol. VII.

DESCARTES, René. Méditation métaphysique, A. T. IX, p. 64; in Euvres, edit. por Charles Adam e Paul Tannery, Paris: Cerf, 11 vol., 1897-1909. Para o texto em latin, cf. A.T. VII, p.81.

DOSSE, François. Maurice Merleau-Ponty: le passeur. Philosophie Magazine, nº 19, 2008.

GUEROULT, M. Descartes selon l'ordre des raisons. Paris: Aubier-Montaigne, 1953.

LEVINAS, E. En découvrant l'existence avec Husserl et Heidegger. Paris: Vrin, 1975.

MARCEL, Gabriel. Existence et objetivité. Revue de Métaphysique et de Morale $\left(1925,32^{\mathrm{e}}\right.$ année, p. 175-195), retomado no $1^{\circ}$ fascículo de Journal métaphysique, Paris: Gallimard, 1927a, p. 309-329.

MARCEL,Gabriel. Journal métaphysique. Paris: Gallimard, 1927b.

MARCEL, Gabriel. Être et avoir. Paris, Montaigne, 1935, [Éditions Universitaires, 1991].

MATTHEWS, E. Compreender Merleau-Ponty. Petrópolis: Vozes, 2010.

\footnotetext{
${ }^{24}$ Em 1934 o segundo projeto de tese de Merleau-Ponty, A natureza da percepção, mostra, pela primeira vez, tanto uma referência à noção de intencionalidade (O primado da percepção e suas consequências filosóficas: PrP, p. 23), embora de forma indefinida, como um interesse pela obra de Husserl. Mas é o texto Christianisme et ressentiment (P 1, p. 9-33) - uma resenha da obra de Max Scheler, L'homme du ressentiment, de 1933 -, que faz da intencionalidade afetiva o elemento essencial para a superação do idealismo. Merleau-Ponty atribui à intencionalidade a tarefa de dar um sentido à vida afetiva, artística, e religiosa. Destaca-se que se Merleau-Ponty toma essa noção fundamental da fenomenologia de Max Scheler, isso significa que ele a situa, primeiro, não no domínio da teoria do conhecimento, mas naquele da vida do desejo.
} 
MERLEAU-PONTY, Maurice. Christianisme et ressentiment. In: Parcours, 1935-1951. Paris: Verdier, 1997, p. 9-33.

MERLEAU-PONTY, Maurice. Être et avoir. In: Parcours, 1935-1951. Paris: Verdier, 1997, p. 35-44.

MERLEAU-PONTY, Maurice. La Structure du Comportement. Paris: PUF, 1967. Trad. Márcia Valéria Martinez de Aguiar. A Estrutura do Comportamento. São Paulo: Martins Fontes, 2006.

MERLEAU-PONTY, Maurice. La Phénoménologie de la Perception. Paris: Gallimard, 1945. Trad. Carlos Alberto. R. de Moura. Fenomenologia da Percepção. São Paulo: Martins Fontes, 1999.

MERLEAU-PONTY, Maurice. O primado da percepção e suas consequências filosóficas. Trad. Constança Marcondes Cesar. Campinas: Cynara, 1989.

MERLEAU-PONTY, Maurice. Sens et non-sens. Paris: Nagel, 1966.

MERLEAU-PONTY, Maurice. L'union de l'âme et du corps chez Malebranche, Biran et Bergson. éd. J.Deprun. Paris: Vrin, 2002.

MERLEAU-PONTY, Maurice. Causeries 1948. éd. Stéphanie Ménasé. Paris: Seuil, 2002. Trad. Fábio Landa e Eva Landa. Conversas - 1948. São Paulo: Martins Fontes, 2004.

MERLEAU-PONTY, Maurice. Résumés de cours. Paris: Gallimard, 1968.

MERLEAU-PONTY, Maurice. Signes. Paris: Gallimard, 1960.

MERLEAU-PONTY, Maurice. La prose du monde. éd. Claude Lefort. Paris: Gallimard, 1969. Trad. Paulo Neves. A Prosa do Mundo. São Paulo: Cosac \& Naify, 2002.

MERLEAU-PONTY, Maurice. Le visible et l'invisible. C. Lefort (éd.) . Paris: Gallimard, 1964. Trad. A. M. Oliveira e J. A. Gianotti. O visível e o invisível. São Paulo: Perspectiva, 1984.

MERLEAU-PONTY, Maurice. L'oeil et l'esprit. Paris: Gallimard, 1964. Trad. Paulo Neves e M. E. G. G. Pereira. O Olho e o Espírito, seguido de A Linguagem indireta e as vozes do silêncio e A dúvida de Cézanne. Prefácio de Claude Lefort. Posfácio de Alberto Tassinari. São Paulo: Cosac \& Naify, 2004.

MERLEAU-PONTY, Maurice. Parcours, 1935-1951. éd. Jacques Prunair. Paris: Verdier, 1997.

MERLEAU-PONTY, Maurice. Parcours deux, 1951-1961. éd. Jacques Prunair. Paris: Verdier, 2000. 
MERLEAU-PONTY, Maurice. A Natureza. Notas, cursos no Collège de France. Trad. Álvaro Cabral. São Paulo: Martins Fontes, 2000.

MERLEAU-PONTY, Maurice. Philosophie et existence. In: Parcours deux, 1951-1961. éd. Jacques Prunair. Paris: Verdier, 2000, p. 247-266.

MOUTINHO, Luiz D. S. O sensível e o inteligível: Merleau-Ponty e o problema da racionalidade. In KRITERION, Belo Horizonte, no 10, Dezembro 2004, p. 264-293.

SAINT AUBERT, Emmanuel De (éd.). Maurice Merleau-Ponty. Paris: Hermann, 2008.

SAINT AUBERT, Emmanuel De. Vers une ontologie indirecte. Sources et enjeux critiques de l'appel à l'ontologie chez Merleau-Ponty. Paris, Vrin, 2006.

SAINT AUBERT, Emmanuel De. Le scénario cartésien. Recherches sur la formation et la cohérence de l'intention philosophique de Merleau-Ponty. Paris: Vrin, 2005.

SAINT AUBERT, Emmanuel De. Du lien des êtres aux éléments de l'être. Merleau-Ponty au tournant des années. 1945-1951. Paris, Vrin, 2004.

SARTRE, J. P. Merleau-Ponty vivant. Les Temps Moderne, $17^{\mathrm{e}}$ année, $\mathrm{n}^{\mathrm{o}}$ spécial 184-185, octobre 1961.

WAHL, Jean. Vers le concret. Études d'histoire de la philosophie contemporaine. Paris: Vrin, 1932. 